\title{
Potential roles and prognostic significance of exosomes in cancer drug resistance
}

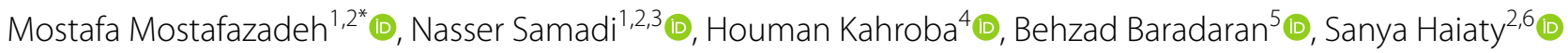 \\ and Mohammad Nouri ${ }^{1,2,7^{*}}$ (1)
}

\begin{abstract}
Drug resistance is a major impediment in cancer therapy which strongly reduces the efficiency of anti-cancer drugs. Exosomes are extracellular vesicles with cup or spherical shape with a size range of 40-150 nm released by eukaryotic cells that contain genetic materials, proteins, and lipids which mediate a specific cell-to-cell communication. The potential roles of exosomes in intrinsic and acquired drug resistance have been reported in several studies. Furthermore, a line of evidence suggested that the content of exosomes released from tumor cells in biological samples may be associated with the clinical outcomes of cancer patients. In this review, we highlighted the recent studies regarding the potential roles of exosomes in tumor initiation, progression, and chemoresistance. This study suggests the possible role of exosomes for drug delivery and their contents in prognosis and resistance to chemotherapy in cancer patients.
\end{abstract}

Keywords: Biomarker, Chemoresistance, Extracellular vesicles, MicroRNAs, Tumor microenvironment

\section{Introduction}

Cancer is a major public health problem and the second most common cause of death in the world [1]. Among several therapeutic strategies, chemotherapy is one of the main approaches for tumor treatment [2]. Although significant advances have been developed for increasing the efficacy of chemotherapeutics, chemoresistance remains a major obstacle against the effective treatment of cancer patients [3]. Exosomes are multi-signal messengers that support cancer development, progression, and chemoresistance by mediating the tumor-tumor and tumorstromal cells interaction [4]. Furthermore, accumulating data suggests that the differential content of exosomes in body fluids can be used as a prognostic factor for cancer therapy and clinical outcomes [5-8]. Here, we describe

\footnotetext{
*Correspondence: mostafa_mostafazade@yahoo.com; nourimd@yahoo.com ${ }^{1}$ Drug Applied Research Center, Tabriz University of Medical Sciences, Tabriz, Iran

2 Department of Biochemistry and Clinical Laboratories, Faculty of Medicine, Tabriz University of Medical Sciences, Tabriz, Iran

Full list of author information is available at the end of the article
}

the structure biological functions of exosomes and their application as nano-carriers for drug delivery. We also discussed how to target these vesicles to increase the effectiveness of chemotherapeutic agents through overcoming chemoresistance.

\section{Structure, content, and biological roles of exosomes}

Exosomes are cup-shaped or spherical extracellular vesicles, these nano-sized vesicles span $40-150 \mathrm{~nm}$ in diameter and weight $1.13-1.19 \mathrm{~g} / \mathrm{mL}$ in density. The exosomes are consisting of a double-layered lipid membrane which surrounds a small fraction of cytosolic content but do not include any cytoplasmic organelles. The content of the exosomes is in direct relation to the physiological status of the mother cell [9]. Exosome membrane is enriched with peripheral and integral proteins including multi-vesicular body biogenesis associated proteins (tumor susceptibility gene 101 protein (TSG101), Alix), adhesion molecules (ICAM-1), MHC I and II molecules, GTPases, heat shock proteins (Hsp60, Hsp70, and Hsp

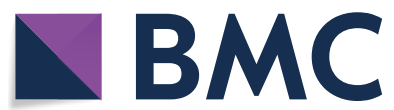

(c) The Author(s) 2020. This article is licensed under a Creative Commons Attribution 4.0 International License, which permits use, sharing, adaptation, distribution and reproduction in any medium or format, as long as you give appropriate credit to the original author(s) and the source, provide a link to the Creative Commons licence, and indicate if changes were made. The images or other third party material in this article are included in the article's Creative Commons licence, unless indicated otherwise in a credit line to the material. If material is not included in the article's Creative Commons licence and your intended use is not permitted by statutory regulation or exceeds the permitted use, you will need to obtain permission directly from the copyright holder. To view a copy of this licence, visit http://creativeco mmons.org/licenses/by/4.0/. The Creative Commons Public Domain Dedication waiver (http://creativecommons.org/publicdomain/ zero/1.0/) applies to the data made available in this article, unless otherwise stated in a credit line to the data. 
90), Rab proteins, clathrin, tubulin, annexins, flotillin-1, cholesterol, ceramides, sphingomyelin and phosphatidylethanolamine which are crucial for the function of exosome during inter-and intra-cellular communication [10, 11]. Tetraspanins (CD9, CD63, and CD81) are the most common surface markers of the exosomes which are widely applied for exosome detection [12,13]. these vesicles carry out different macromolecules as their cargo, including DNA, mRNA, microRNA, long non-coding RNA (lncRNAs), lipids, and proteins [10]. Exosome biogenesis initiates during inward budding of late endosomal membrane which results in the formation of intraluminal vesicles (ILVs) within multivesicular endosomes or multivesicular bodies (MVBs). Endosomal sorting complex required for transport proteins (ESCRT-0, I, II, and III) participate in direction of ILVs toward selective cargo loading [14]. Capable MVBs for releasing as exosome can move toward cell membrane and secret ILVs into extracellular milieu under control of Rab GTPases 27A and B molecular motors, also the MVBs which are not capable of releasing as exosome can fuse with lysosomal compartment for degradation and recycling of the components [15]. The general structure, composition, and biogenesis of exosomes are summarized in Fig. 1.

Exosomes can be secreted by almost all eukaryotic cell types, and they are traceable in body fluids such as blood, urine, saliva, cerebrospinal fluid (CSF), amniotic fluid, breast milk, synovial fluid, and ascites [16, 17]. The biological functions of exosomes rely on the cells of origin and the status of the originated tissue or cell at the time of exosome biogenesis. Normally, cells expel toxic or redundant nonfunctional cellular components including drugs via exosomes to maintain the cellular homeostasis [18]. The persistent presence of exosomes in biological body fluids and extracellular spaces suggests their important role in the cell-cell communication network and it has been shown that these nano-vesicles play significant roles in biological processes (e.g. antigen presentation, coagulation, cellular homeostasis, angiogenesis, apoptosis, and synaptic physiology) and various pathological conditions including autoimmune and neurodegenerative diseases, infectious diseases, inflammation, and cancers $[16,19,20]$.

\section{Exosome and cancer drug resistance}

Drug resistance is defined as the reduction in effectiveness and potency of medication to produce therapeutic merits which is a major obstacle in cancer treatment [21]. To the best of our knowledge, resistance to anticancer drugs can be categorized into two main classes, intrinsic (pre-existent) and acquired drug resistance [22]. In the intrinsic drug resistance, resistance-associated factors (e.g. presence of cancer stem cells) exist in the tumor mass before any drug exposure [23], while acquired drug resistance or multi-drug resistance (MDR) is a slow and stepwise process which force tumor cells to undergo genetic mutations or epigenetic changes during treatment which results in drug-resistant phenotype [24]. Acquired drug resistance can be attributed to the decreased intracellular concentration of chemotherapeutic agents, altered expression of oncogenes or tumor suppressor genes, enhanced DNA damage repair, epithelial-mesenchymal transition (EMT), autophagy $[25,26]$, and highly acidic microenvironment of tumors [27]. Recently an ever-increasing body of evidence highlighted the significant role of exosomes in modulating the tumor-specific chemoresistance strategies that lead to the induction of tumor drug resistance [28, 29]. Here, we describe the potential roles of exosomes in the establishment of therapeutic resistance in cancer (Fig. 2).

\section{Exosomes and drug efflux}

Increased efflux of chemotherapeutic agents, which leads to declined intracellular drug concentration, has been considered to be the main cause of drug resistance in cancer [30]. One of the mechanisms by which tumor cells reduce intracellular levels of cytotoxic substances is the secretion of the exosomes to eliminate the cytotoxic effects of anti-cancer agents. Cancer cells can simply prevent the function of these agents and their metabolites by encapsulating them in exosomes to remove out them from the cell [31]. In prostate cancer, Enzalutamide (ENZ)-resistant cells release significantly higher amounts (2-3 fold) of exosomes compared to respective sensitive cells, also it has been shown that these resistant cells use exosomes to remove Enz out of the cell to reduce the drug concentration [32]. Similarly, Koch et al. showed that B-cell lymphoma cells could eliminate doxorubicin and pixantrone through exosome secretion, and that exosome biogenesis inhibition via indomethacin or genetic depletion of ABCA3 enhances intracellular accumulation and cytostatic activity of both drugs in vitro as well as in vivo experiments [33]. Furthermore, Wang et al. indicated that treatment of breast and ovarian cancer cell lines with paclitaxel or doxorubicin significantly increase exosome release in a time and dose-dependent manner, the exosomes isolated from these cells contain a considerable concentration of the drug, and these exosomes have cytotoxic effects on recipient cells [34]. In addition to facilitating drug efflux by exosomes, drug exporter pumps, such as P-glycoprotein (P-gp/MDR1), multidrugresistant protein-1 (MRP-1), and breast cancer resistance protein (BCRP/ABCG2) participate in drug efflux from the cells, therefore overexpression of these pumps in tumor cells can decrease the drug bioavailability and establish drug resistance [35, 36]. Several studies have 


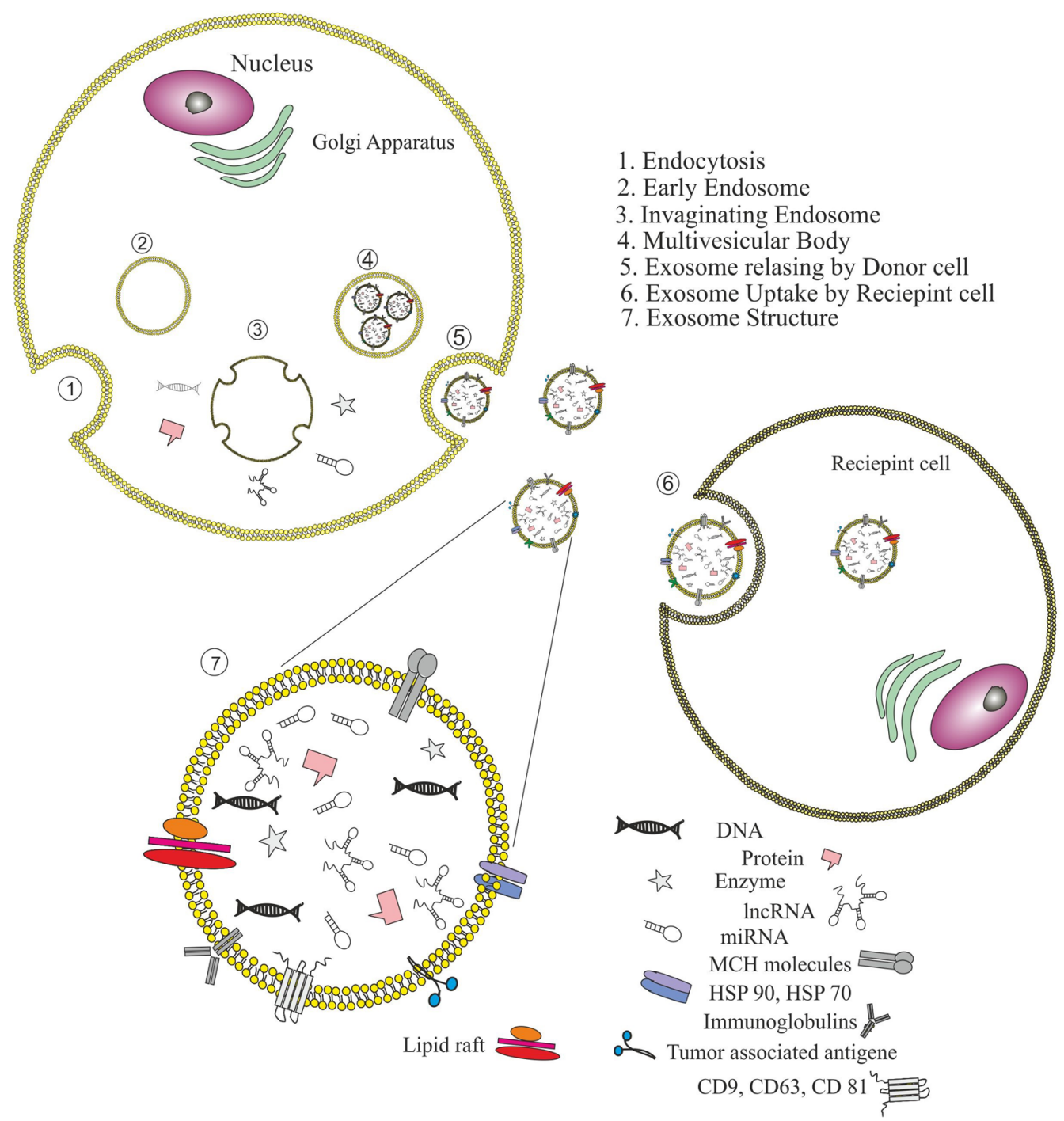

Fig. 1 a Exosomes are cup/spherical-shaped vesicles $(40-150 \mathrm{~nm}$ ) with a double-layered lipid membrane surrounding a small cytosol without any organelles. This phospholipid bilayer membrane loaded with peripheral and integral proteins. Exosomes also contain nucleic acids (e.g. DNA, mRNAs, microRNAs, and long non-coding RNAs) and lipids. b Exosome biogenesis started via endocytosis pathway and early endosome formation. During this process, the cell membrane components (proteins and etc.) are embedded into the early endosomes' membrane, which then matured into late endosomes. Inward budding of late endosomal membrane creates multiple intraluminal vesicles (ILVs) within multivesicular endosomes, in which some particular proteins and other cytosolic constituents are enveloped in exosomes under control of ESCRT family. MVBs then fuse with the cell membrane to release their ILVs into extracellular milieu by Rab GTPases 27A and B molecular motors

shown that exosomal transportation of P-gp induces chemoresistance phenotype in recipient tumor cells [3744]. For instance, Corcoran et al. revealed that exosomes derived from docetaxel-resistant prostate tumor cells induce docetaxel-resistance in drug-sensitive cells, which may be partially due to exosomal delivery of MDR-1/Pgp. Also, exosomes isolated from the serum of patients with increasing PSA levels (non-respondent to docetaxel) could protect prostate tumor cells from the cytotoxic effects of docetaxel [38]. Another study has shown that exosomes released from doxorubicin-resistant osteosarcoma cells induce a resistant phenotype in recipient cells by delivering MDR-1 mRNA and its product P-glycoprotein [43].

\section{Exosomes and cancer stem cell-mediated drug resistance}

Cancer stem cells (CSCs), a small subset of cancer cells with self-renewal and multi-differentiation capacities, play a critical role in tumor initiation and progression. 


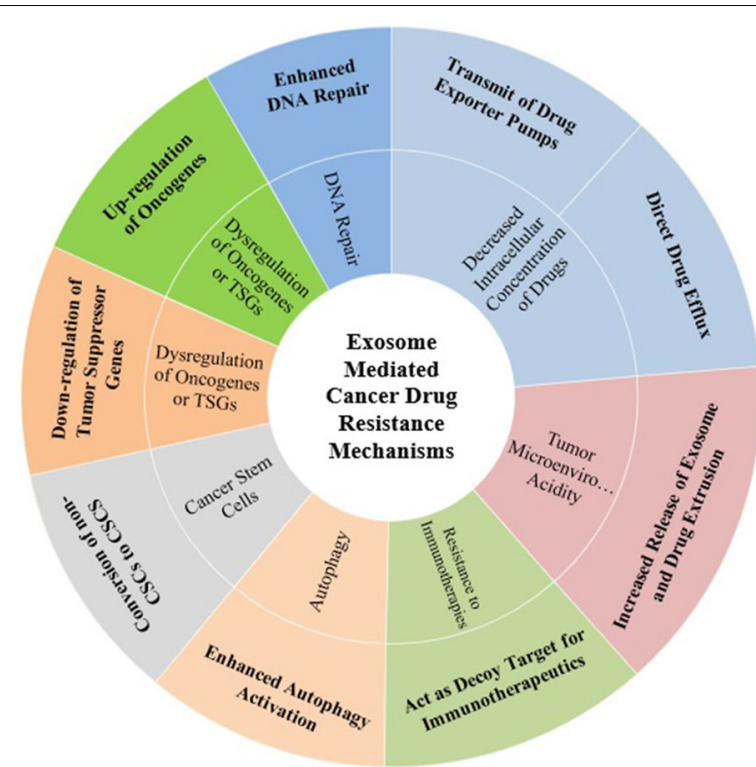

Fig. 2 Exosome mediated cancer drug resistance mechanisms

Recent studies revealed that the presence of CSCs within tumor mass is the main cause of cancer therapy resistance, leading to tumor relapse and ultimately metastasis $[45,46]$. Due to their upregulated expression of drug efflux transporters (i.e., P-gp, ABCG2) and other chemoresistance related genes, these highly tumorigenic stem cells are inherently resistant to chemotherapeutic agents [47]. In addition to drug resistance, this rare population has a high tumorigenicity capacity, which enables them to repopulate a tumor after chemotherapy. In this regard, several studies have shown that recurrent tumors after chemotherapy failure are often enriched in cells that expressing CSC markers [48, 49], however, the origins of CSCs are not yet clear and controversial [46]. The accumulated knowledge suggest that CSCs could be derived from cancer cells/differentiated cells that acquired stemlike characteristics through reprogramming and dedifferentiation [50].

A body of evidence confirms that exosomes, as a mediator of intercellular communication in the TME, participate in the conversion of non-CSC to CSCs via delivering stemness and EMT promoting factors. Snail1, a zinc finger transcriptional factor that promotes the repression of E-cadherin expression, is shared by cancer-associated fibroblasts (CAFs) derived exosomes to induce EMT and establishment of lung cancer cells with CSC characteristics [51]. Fibroblasts-derived exosomes contain IL-6, Activin-A, and granulocyte colony-stimulating factor (G-CSF) which are interacted with lung carcinoma cells to induce gene expression alterations, most probably through STAT3 and Smad activation. The consequent activation of stemness-associated pathways such as Wnt, Notch, and Hedgehog direct tumor cells' dedifferentiation of lung cancer cells to a more CSC-like phenotype and reduces cell cycle progression, which is associated with higher methotrexate resistance [52]. Similarly, exosomal Wnt derived from fibroblasts induces resistance to 5-fluorouracil (5-Fu) via reprogramming differentiated colorectal cancer (CRC) cells to functional CSCs [53].

In addition to exosomal protein cargo, several exosomal miRNAs are also reported to be involved in the EMT-associated chemoresistance. For instance, exosomal delivery of oncomiRNA-155 from CSCs and resistant breast cancer cells to sensitive breast cancer cells mediates the loss of C/EBP- $\beta$, which in turn, causes loss of TGF- $\beta$ and leads to EMT and chemoresistance in recipient cells [54]. CAFs secreted exosomes contain miR-92a-3p which can induce 5-FU/L-OHP resistance by promoting cell stemness and EMT in CRC through targeting FBXW7 and MOAP1 [55]. In CRC, it has been shown that fibroblast-derived exosomes can develop chemoresistance to 5-FU or oxaliplatin through increasing CSCs percentage, clonogenicity, and tumoral growth [29]. Together, these results depict that exosomes could promote the dedifferentiation of cancer cells to CSCs and the development of chemoresistance, and propose that interfering with exosome release and uptake may help to increase chemosensitivity of cancers to available chemotherapeutics.

\section{Exosomes and autophagy induced drug resistance}

Autophagy (or macro-autophagy) is a highly conserved catabolic mechanism for the destruction and recycling of redundant or dysfunctional cellular components, in which a specialized double-layered membrane vesicle called autophagosome is formed around the unnecessary cellular constituent or intracellular pathogen, which eventually fuses with the lysosome to degrade the confiscated material [47]. Autophagy activation normally occurs in cells in response to environmental stressors, facilitates cell survival, and can establish drug resistance in malignant cells [56]. Increased activity of autophagy and improved secretion of exosomes from tumor cells after chemotherapy have been documented in several studies, indicating that these responses are part of the cells' response to stress conditions due to chemotherapy and survival mechanisms against chemotherapies $[57,58]$. In support of this possibility, the potential role of exosomes in autophagy-mediated therapy resistance has been reported in different types of cancers. For example, Gefitinib, a tyrosine kinase inhibitor, is widely used for the treatment of non-small cell lung cancer (NSCLC) patients with EGFR mutations, but its combination with Platinum-based antineoplastic drugs leads to 
an antagonistic effect. Exosome isolated from gefitinibtreated EGFR-mutant NSCLC cells conditioned medium decreased the anti-neoplastic effects of cisplatin by increasing autophagic activity and reducing apoptosis, as confirmed by an increasing Bcl-2/Bax ratio, upregulation of LC3-II, and downregulation of p62 protein levels [59]. Similarly, exosomal mediated transmit of miR-425-3p enhanced autophagy activation in the recipient NSCLC cells via targeting AKT1, eventually leading to resistance to cisplatin [60]. In hepatic cancers, exosomes secreted from HBV-infected cancer cells can downregulate cell apoptosis and promote oxaliplatin resistance via activating the chaperone-mediated autophagy (CMA) pathway through upregulation of lysosome-associated membrane protein (Lamp2a) as a key molecule in CMA pathway [61]. More interestingly, exosomal transmit of miR-567 from normal breast epithelial cells (MCF-10A) resensitized resistant breast cancer cells to trastuzumab by targeting autophagy-related 5 (ATG5) and thereby inhibiting autophagy [62]. These studies demonstrate the possible capacity of the crosstalk between cancer cells derived exosomes and autophagy phenomenon in cancer therapy response.

\section{Role of exosomes in dysregulation of oncogenes or tumor suppressor genes expression}

Oncogenes and tumor-suppressor genes (TSGs) are two broad classes of genes that play crucial roles in oncogenesis by opposite mechanisms. Oncogenes encoded proteins (Onco-proteins) promote normal cell growth while TSGs encode proteins inhibit the survival of malignant cells. Several reports indicated that TSGs and oncogenes are important mediators of drug resistance [63]. Exosomes have been shown to alter the expression of TSGs and oncogenes through the intercellular translocation of noncoding RNAs.

TP53 is the most studied TSGs and is mutated in more than half of human cancers which participates in cell cycle arrest and apoptosis following DNA damage through transcriptional activation of pro-apoptotic genes or sequestration of anti-apoptotic proteins. Alteration in TP53 expression or its function is often correlated with resistance to standard antineoplastic agents [64]. In prostate cancer, exosomal miR-27a could induce resistance to cisplatin, docetaxel, and doxorubicin in recipient cells by the degradation of p53 mRNA [65]. Down-regulation of PTEN expression, a negative regulator PI3k/Akt signaling pathway, results in reduced dephosphorylation of PIP3 and enhances cell survival and proliferation [63]. Recently, it has been reported that transferring exosomal miR-32-5p from resistant cells to sensitive cells can activate the PI3K/Akt pathway by targeting PTEN and disseminating resistance to 5 -FU by promoting angiogenesis and EMT [66]. CAV1 encodes Caveolin1, a negative regulator of EGFR activation, which acts as a tumor suppressor gene in glioblastoma (GBM) cells. Exosomal delivery of bioactive miR-1238 from temozolomide (TMZ) resistant cells can provoke chemoresistance through triggering the EGFR-PI3K-AKT-mTOR pathway in sensitive GBM cells [67]. CAFs are inherently resistant to gemcitabine (GEM) and CAF derived exosomes contain miR-106b which promotes GEM resistance in pancreatic cancer cells by direct targeting of TP53INP1 [68]. Furthermore, exosomal miR-155-5p increases paclitaxel resistance in recipient gastric cancer cells via GATA3 and TP53INP1 downregulation [69].

In addition to miRNAs, tumor-derived exosomes also induce chemoresistance in drug-sensitive cells via transferring of lncRNAs [70, 71]. Sunitinib, a receptor tyrosine kinase (RTK) inhibitor, is the first-line treatment for renal cell carcinoma (RCC) patients, which has potent anti-angiogenic and anti-tumor activities by inhibition of VEGF receptor, PDGF receptor, FMS-like tyrosine kinase 3 (FLT3), and stem cell growth factor receptor. Qu et al. showed that exosomes can share lncARSR which induces sunitinib resistance via competitively binding miR-449/miR-34 to increase c-MET and AXL expression in RCC cells [72]. Similarly, exosomal delivery of lncRNA PART1 disseminates gefitinib resistance in esophageal squamous cell carcinoma by regulating miR-129/Bcl-2 pathway [70]. Treatment of drug-sensitive breast cancer cells with exosomes derived from trastuzumab-resistant cells that highly expressing lncRNA-SNHG14 can confer trastuzumab resistance by targeting the $\mathrm{Bcl}-2 / \mathrm{Bax}$ signaling pathway [73]. Exosomal lncRNA CCAL from CAFs directly interacts with human antigen R (mRNA stabilizing protein $\mathrm{HuR}$ ), enhances $\beta$-catenin expression at both mRNA and protein levels, and promotes oxaliplatin resistance in CRC cells [74].

Besides, exosomes have been shown to directly transduce oncogenes into the sensitive cells to induce drug resistance. For instance, MET is shared by GBM cells harboring PTPRZ1-MET fusion to establish temozolomide resistance in GBM cells [75]. Survivin, a member of the inhibitor of apoptosis (IAP) protein family, can be regarded as an oncogene, aberrant overexpression of this molecule induces resistance to apoptotic stimuli and chemotherapeutic agents. It has been shown that exosomal transferring of survivin promotes paclitaxel resistance in breast cancer cells [76]. Anaplastic lymphoma kinase (ALK) is an RTK that can be activated by mutations and acts as an oncogene in different cancers. Cesi et al. showed that a novel truncated form of ALK can be shuttled by vemurafenib resistant melanoma cell-derived exosomes and promote resistance phenotype in recipient cells [77]. Moreover, exosome-mediated transfer of 
p-STAT3 from resistant cells significantly promoted cell survival and 5-FU resistance both in vitro and in vivo [78].

\section{Exosomes and enhanced DNA repair in tumor cells}

Most chemotherapeutic agents, including platinumbased drugs, 5-FU, and TMZ, target tumor cells by inducing DNA damage, which can initiate a variety of signaling pathways called DNA damage response (DDR) [79] comprising DNA lesion detection, signal transduction, cell cycle checkpoints activation, and DNA repair, which may elicit resistance to clinical DNA-damaging agents through increasing DNA repair [80]. Also, the potential role of exosomes in enhancing DNA repair and promoting cancer cell survival has been confirmed in several studies. For example, X-ray repair cross complementing 4 (XRCC4), a major factor for double-strand breaks (DSBs) repair, has recently been shown to be connected with TMZ resistance in tumor cells. Zhang et al. revealed that exosomal lncRNA SBF2-AS1 provokes TMZ resistance in recipient cells. Mechanistically, IncRNA SBF2AS1 acting as a competing endogenous RNA (ceRNA) for miR-151a-3p, leads to the disinhibition of its endogenous target, XRCC4, which enhances DNA lesions repair in tumor cells [81]. In another study, it has been shown that exosome-mediated transferring of miR-151a re-sensitize GBM-resistant cells to TMZ by targeting XRCC4 [82]. MGMT $\left(\mathrm{O}^{6}\right.$-methylguanine DNA methyltransferase) is the key enzyme involved in TMZ-induced DNA damage repairing and its tissue-level expression is negatively correlated with the treatment efficacy. Exosomal delivery of MGMT mRNA from reactive astrocyte to glioma cells confers TMZ resistance phenotype [83].

\section{Tumor microenvironmental acidity and exosome-mediated chemoresistance}

The tumor microenvironment (TME) is acidic, in vivo ranges from 6.5 to 7.1, which is a common phenotype of virtually all tumors and the TME acidity is directly related to the tumor malignancy [27]. Altered glycolytic activity due to the overexpression of M2-PK (a dimeric isoenzyme of pyruvate kinase) and hypoxia, the so-called "Warburg Effect", causes a large accumulation of lactic acid and proton $\left(\mathrm{H}^{+}\right)$within the tumor cell cytoplasm, which contributes to TME acidification [84]. Also, high amounts of carbon dioxide are produced during mitochondrial respiration in oxygenated tumor cells, which also contributes to the significant release of protons into the TME [85].

Decreased extracellular $\mathrm{pH}$ induces a selective pressure result in the selection of tumor cells that promotes cancer drug resistance [86], which one of the common phenomena associated with this selection is increased exosome secretion [87].

There is strong evidence that a low $\mathrm{pH}$ potentially influencing exosome release and uptake by tumor cells [88]. Recently it has been shown that tumor acidity increases exosome secretion in human tumor cells from different cancer, including melanoma, osteosarcoma, colon, prostate, and breast cancer [89]. The underlying mechanism of increased exosome extrusion under acidic conditions is unclear; however, one of the main and well-known functions of the exosome is the removal of toxins, including chemotherapeutics, from the cell cytoplasm [84]. High acidity extracellular environment may likely induce an amplified exosome secretion for detoxifying purposes. In this regard, several investigations have indicated that resistant cancer cells secrete larger amounts of exosomes than their sensitive counterparts [90, 91]. Furthermore, the results of some recent experiments in vitro revealed that the acidic extracellular environment increases the number of released exosomes along with upregulation of certain tumor biomarkers such as carbonic anhydrase IX (CA IX) and prostate specific antigen (PSA) in cancer cells and their exosomes [17, 92].

Therefore, considering the effect of environmental acidity on exosome secretion and chemoresistance, an anti-acid approach can be proposed as a winning strategy in cancer treatment, which may be achieved with buffers or proton pump inhibitors (PPIs) [89]. Recent studies have verified that the alkalization of tumor cell environment with buffers causes a sharp decrease in exosome secretion [93]. Furthermore, two different studies have demonstrated that buffering the tumor environment decelerates tumor growth of xenografts in mice and enhances responsiveness to chemotherapeutics in human and veterinary patients $[94,95]$. Moreover, pre-treatment of human melanoma cells Lansoprazole (a PPIs) prevents tumoral exosome secretion leading to improved cisplatin-dependent cytotoxicity [96].

\section{Exosomes and resistance to immunotherapies}

Several studies have suggested that tumor cells produce and secrete exosomes that act as a decoy target for anticancer immunotherapies. Trastuzumab (Herceptin), a humanized monoclonal antibody targets the extracellular domain of human epidermal growth factor receptor 2 (HER2) inhibits tumor cells' survival and proliferation, and is widely used as an approved medication for early HER2 positive and advanced metastatic cancers. It has been shown that HER2-overexpressing breast cancer cells, release HER2-containing exosomes which interfere with the therapeutic activity of Herceptin. Exosomal surface expression of HER2 allows the exosome to compete with breast cancer cells for Trastuzumab binding, 
thus restraining bioavailability and decreasing Trastuzumab anti-cancer efficiency [97]. In breast cancer, Han et al. showed that exosomal lncRNA AFAP1-AS1 (actin filament associated protein 1 antisense RNA 1) could promote Herceptin resistance through associating AUbinding factor 1 (AUF1) and HER-2 protein levels upregulation [62].

Rituximab, a chimeric antibody against cell surface CD20 antigen, exerts its cytolytic effects via direct induction of apoptosis, antibody-dependent cytolysis, as well as complement-dependent cellular cytotoxicity, and is used in aggressive B-cell lymphoma immunotherapy. B-cell lymphoma cells secrete CD20 carrying exosomes, which bind and deplete therapeutic anti-CD20 antibodies, leads to complement components depletion, and shield cancer cells from antibody attack [98].

\section{How to combat exosome-induced drug resistance}

Given the above, the potential role of exosomes in cancer therapy resistance can be understood, therefore, to maximize the efficacy of chemotherapy, eliminating the detrimental effect of exosomes on cancer therapy seems to be necessary. To this end, several approaches have been proposed including inhibition of exosome biogenesis and release, inhibition of their uptake by recipient cells, and targeting their cargo. Some pharmacological and chemical compounds have been used to sensitize cancer cells to chemotherapeutic agents via targeting biogenesis, release, and exosome uptake which have been summarized in Table 1. For instance, in leukemia and lymphoma, it has been found that high expression of ATP-binding cassette transporter A3 (ABCA3) is crucial for exosome generation and chemoresistance and pretreatment of diffuse large B-cell lymphomas (DLBCL) with indomethacin, a COX inhibitor, enhances the accumulation of doxorubicin and pixantrone in the nuclei of DLBCL tumor cell through the reduction in ABCA3 levels and exosome biogenesis, which increases tumor cell susceptibility to these drugs [33]. Manumycin A, a natural microbial metabolite with a potent selective Ras farnesyl-transferase inhibitory activity, decrease exosome biogenesis and secretion by inhibition of Ras/Raf/ERK1/2 signaling pathway and consequent inhibition of the oncogenic splicing factor hnRNP H1 in castration-resistant prostate cancer cells [99]. In another study, it has been shown that pre-treatment of tumor cells (MCF7, HeLa, and BT549) with ketotifen, an anti-histamine which acts as a calcium channel blocking agent, reduces exosome release and increases the sensitivity of cancer cells to doxorubicin by enhancing intracellular drug retention [100]. Similarly, 5-FU mediated apoptosis was significantly increased in prostate and breast cancer cell lines in the presence of a combination of chloramidine and bisindolylmaleimide-I, which act as inhibitors of exosome release [101]. Exosomes interact and are taken up by recipient cells in various mechanisms such as direct integration with the cell membrane, clathrin and caveolin1-mediated endocytic pathways, cholesterol/lipid rafts-dependent endocytosis, macro-pinocytosis, phagocytosis, and ligand-receptor interaction. As a result, targeting the aforementioned mechanisms can prevent the internalization of the exosomes. On such a basis, several researchers have attempted to overcome the chemotherapy resistance through inhibition of exosome uptake by target cells. To et al. reported that exosome uptake inhibition by dynasore, dynamin GTPase activity inhibitor, prevents ABCG2 induction and sensitizes the resistant colorectal cancer cells to SN38 treatment [102]. Heparan

Table 1 Chemical and pharmacological agents for targeting exosome biogenesis, secretion, and uptake

\begin{tabular}{|c|c|c|c|}
\hline & Drug/Compound & Mechanism & Ref. \\
\hline \multirow{6}{*}{$\begin{array}{l}\text { Inhibition of exosome } \\
\text { biogenesis and secre- } \\
\text { tion }\end{array}$} & GW4869 & Targeting neutral sphingomyelinase 2 & {$[29]$} \\
\hline & Manumycin & Inhibition of Ras/Raf/MEK/ERK1/2 signaling pathway & [99] \\
\hline & Indomethacin & Blocking the expression of $\mathrm{ABCA}-3$ & {$[33]$} \\
\hline & Ketotifen & Unknown & [100] \\
\hline & Chloramidine and bisindolylmaleimide-l & Unknown & [101] \\
\hline & Lansoprazole (proton pump inhibitor) & Decreasing microenvironmental acidity & {$[96]$} \\
\hline \multirow{7}{*}{$\begin{array}{l}\text { Inhibition of exosome } \\
\text { internalization }\end{array}$} & Heparin & Inhibition of HSPG mediated endocytosis & [104] \\
\hline & Cytochalasin D & Inhibition of actin polymerization & [105] \\
\hline & Dynasore & Inhibition of the GTPase activity of dynamin & [106] \\
\hline & Chlorpromazine & Inhibition of clathrin-dependent endocytosis & {$[107]$} \\
\hline & Methyl- $\beta$-cyclodextrin & Remove cholesterol from the cell membrane & [108] \\
\hline & Nystatin and Simvastatin* & $\begin{array}{l}\text { Inhibition of the lipid raft -mediated endocytosis } \\
\text { pathway/*Inhibitor of HMG-CoA }\end{array}$ & [109] \\
\hline & Filipin III & Inhibitor of lipid raft dependent and caveolar endocytosis & [88] \\
\hline
\end{tabular}


sulfate proteoglycans (HSPGs) acts as cell surface receptors for exosome uptake and internalization [103]. Pretreatment of oral squamous carcinoma cells (OSCCs) with heparin, a competitive inhibitor of HSPG mediated endocytosis, inhibits exosome uptake by recipient cells and suppresses the exosome induced tumor progression in vitro and in vivo [104].

In addition to inhibiting biogenesis, release, and uptake of exosomes, exosome cargo targeting could also be an approach to overcome exosome-induced drug resistance. In esophageal cancer, exosome-mediated transferring of MiR-21 provokes cisplatin-resistant phenotype in recipient cells through targeting programmed cell death 4 (PDCD4) mRNA and downregulating its protein level. It has been shown that cell transfection with anti-miR-21 (the antisense oligonucleotide sequence of miR21) inhibits exosome induced chemoresistance, which raises the possibility that anti-exosome miR-21 can act as a potentially useful target for overcoming cisplatin resistance in patients with esophageal cancer [110]. Similarly, in vitro and in vivo inhibition of exosomal miR-214 with antagomir, re-sensitize resistant NSCLC cells to gefitinib [111]. As previously mentioned, the intercellular transmission of lncARSR by exosomes promotes sunitinib resistance in renal cell carcinoma cells, and lncARSR targeting with locked nucleic acids significantly rescinded the sunitinibexosome-mediated resistance [72].

\section{Exosomes as a natural capsule for drug delivery to overcome tumor drug resistance}

The role of exosomes as a natural vehicle of protein, mRNA, and noncoding RNAs among cells, leads to the idea that they can be used as a delivery system for overcoming chemoresistance. In this context, there is a considerable body of research that shows the efficacy of exosomes in drug or gene delivery due to their ability to pass through the lipid bilayer cell membrane. Exosomes as a natural product of the body have many advantages over the other synthetic nano-carriers for drug or gene delivery, such as low immunogenicity, high biocompatibility and, and high efficacy of delivery [112]. Also, exosomes have good stability in the circulation, which allows them to travel long distances within the body and deliver their cargo to target cells under both physiological and pathological conditions. Furthermore, exosomes have a cytosol like core, which makes them suitable carrier for water-soluble drugs [113]. Today, these natural nanoparticles are widely used as delivery systems for conventional drugs, genes, and other natural compounds. The successful delivery of paclitaxel by exosomes in vitro laid the foundation for exosomes carrying anticancer drugs for in vivo tumor therapy [112]. Kim et al. demonstrated that the incorporation of paclitaxel into exosomes increases cytotoxicity more than 50 times in drug-resistant (P-glycoprotein + ) cells [114]. Saari et al. also showed that exosome-mediated delivery of paclitaxel enhances the cytotoxicity of this drug in autologous prostate cancer cells [115]. Several studies have shown that exosomal encapsulation of doxorubicin reduces the doxorubicininduced cardiotoxicity in mice. Therefore, a higher concentration of doxorubicin can be used for cancer treatment, which in turn increases the efficiency of doxorubicin [116-118]. Moreover, Yang et al. have reported that brain endothelial cell-derived exosomes can pass anticancer agents across the blood-brain barrier (BBB) for the treatment of brain tumors [119]. More interestingly, in another study cow milk-derived exosomes have been used for delivery of the chemo-preventive and chemotherapeutic drugs. In this report, paclitaxel and docetaxel-loaded exosomes showed significantly higher efficacy compared to the free drug in cell culture studies and against lung tumor xenografts in vivo [120]. Acridine Orange (AO) is an organic acidophilic dye with a potent tumor-killing effect after activation by a light source at $466 \mathrm{~nm}$ (blue light). However, the clinical use of OA is restricted by its potential systemic toxicity. Iessi et al. demonstrated the exosome-mediated transfer of $\mathrm{OA}$ increase the delivery and the efficacy of AO in human melanoma cells [121].

In addition to conventional drugs, various genetic materials such as short interfering RNA (siRNA) and miRNA can also be delivered by exosomes to overcoming drug resistance in tumor cells. Sorafenib is an effective clinical drug in the treatment of hepatocellular carcinoma (HCC) and GRP78 (a member of the HSP family) which is overexpressed in sorafenib resistant cancer cells compared to sensitive cells. Exosomal delivery of siRNA against GRP78 (siGRP78) suppresses sorafenib resistance in HCC [122].

Further studies have indicated that miRNAs can also be delivered by exosomes. For example, in triple-negative breast cancer cells, miR-134-enriched exosomes derived from miR-134-transfected cells decreased aggressiveness, migration, and enhanced sensitivity to anti-Hsp90 drugs in parent cells (with low endogenous miR-134 levels) via down-regulation of STAT5B-Hsp90 [123]. Similarly, Zeng et al. indicated that exosome-mediated transferring of miR-151a to temozolomide-resistant glioblastoma cells enhances chemo-sensitivity to temozolomide [82]. As well as, exosomal miR-122 and miR-199 delivery by mesenchymal stem cell-derived exosomes improved the chemosensitivity of HCC cells respectively to sorafenib [124] and 5-fu [125] in vitro and in vivo studies. It has been shown that miR-9 is involved in the expression of P-glycoprotein and exosomal transferring of anti-miR-9 could confer chemo-sensitivity in glioblastoma multiform 
cells [126]. Furthermore, treatment of HepG2 cells with miR-744-enriched exosomes inhibited proliferation and sorafenib resistance in HCC through targeting paired box gene 2 (PAX2) [127]. Similarly, exosomes derived from the conditioned media of transfected bone marrow stromal cells with a miR-146b expression plasmid significantly reduces tumor growth in vitro and a rat xenograft model of brain tumor [128]. More excitedly, Liang et al. used engineered exosomes for targeted co-delivery of 5-FU and miR-21 inhibitor to reverse chemoresistance in colon cancer. They showed that exosomal co-delivery of 5-FU and miR-21 inhibitor effectively resensitize resistant cells to 5-FU [129].

\section{Exosomes as predictive biomarkers for clinical outcome of chemotherapy}

Multi-drug resistance, undesirable chemotherapeutic agents' side effects, and tumor cell dissimilarity among and within the cancer patients restrict the efficacy of anticancer drugs. To overcome these obstacles, predictive biomarkers (e.g. tumor-derived exosomes) have recently emerged to guide oncology specialists in the selection of proper chemotherapy drugs for the treatment of various cancer patients [130]. Exosomal cargo properly reflects the features of releasing cells and their metabolic status. For this reason and because of their abundance in biological fluids, accessibility, high circulation stability, selective cargo sorting, and reproducibility, exosomes represent a valuable and non- or semi-invasive biomarker for cancer diagnosis and prognosis [131-134]. There is an increasing interest in using tumor-derived exosomes as easily accessible biomarkers in predicting the clinical outcome of chemotherapy $[8,135-137]$. A recently conducted study suggested that high exosomal expression of the oncogenic lncRNA UCA1 (urothelial carcinoma-associated 1) might predict cetuximab resistance in CRC patients [137]. A panel of serum-derived exomiRs (miR-96-5p, miR-21-5p, miR-1229-5p, and miR-1246) is suggested as a predictive biomarker for chemoresistance in CRC patients [138]. Elevated serum-derived exomiR-92a-3p is proposed as a prognostic marker for metastasis and 5 -Fu/Oxaliplatin resistance in CRC patients [55]. Modified fluorouracil, leucovorin, and oxaliplatin (mFOLFOX6)-based chemotherapy is the first-line treatment for metastatic CRC. It has been reported that plasma exomiR-125b levels may serve as a useful biomarker for mFOLFOX6)based first-line chemotherapy resistance in advanced and recurrent CRC cancer patients [139]. Microtubuletargeting chemotherapy agents such as docetaxel and paclitaxel are currently used as the first-line chemotherapy for castration-resistant prostate cancer (CRPC) patients. Serum derived exosomes containing CD44v8-10 mRNA, have been proposed as a potential element for docetaxel-resistance predicting among prostate cancer patients [140]. Circulating exosomal Integrin $\beta 4$ (ITGB4) and vinculin (VCL) could predict taxane-resistance in prostate cancer patients [141]. Higher plasma levels of exomiRs (miR-1290 and miR-34a) are related to poor response to docetaxel in metastatic CRPC patients [142, 143]. P-gp, which acts as a drug exporter pump, contributes to the expansion of drug resistance in different cancer types. It has been suggested that serum exosomal P-gp in prostate cancer patients could be a useful marker for docetaxel resistance diagnosis [39]. Another study has shown that resistance to hormonal therapy in metastatic prostate cancer patients may be predicted by detecting androgen receptor splice variant 7 (AR-V7) in plasmaderived exosomal RNA [144].

Wang et al. demonstrated that circulating exosome carrying transient receptor potential channel 5 (TRPC5) might act as a noninvasive chemoresistance biomarker for breast cancer patients [145]. Glutathione S-transferase P1 (GSTP1), a xenobiotic-metabolizing enzyme that plays an important role in the detoxification of chemotherapy agents through conjugating them with glutathione, has been shown that enriched in adriamycin-resistant breast cancer cell-derived exosomes and plasma-derived GSTP1-containing exosomes could predict response to chemotherapy drugs in breast cancer patients [136]. Exosomal enrichment of lncRNASNHG14 and survivin in human serum is another diagnostic biomarker for drug-resistant breast cancer $[73,76]$.

In pancreatic cancer, exosomal expression of Ephrin type-A receptor 2 (EphA2) could serve as a minimallyinvasive predictive biomarker for responding to GEM [146]. Clinically, high levels of lncSBF2-AS1 in serum exosomes were associated with poor response to TMZ treatment in GBM patients [81]. Different exosomal cargos including miRNAs, LncRNAs, and proteins are previously described as predictive markers in tumor drug resistance which are listed in Table 2.

\section{Conclusion}

The rapid development of drug resistance in tumor cells is one of the most important barriers to cancer treatment, and success in this field depends on a thorough understanding of the molecular mechanisms involved in drug resistance, as well as the complexities of interaction between different components of the tumor microenvironment. Exosomes are intracellular endosomal origin nano-vesicles that are produced and secreted by all eukaryotic cell types in normal and pathological conditions and play a key role in maintaining cellular homeostasis, as well as intra and intercellular communication. Distribution of biological molecules 
Table 2 Predictive role of exosomal cargo in tumor drug resistance

\begin{tabular}{|c|c|c|}
\hline Cancer type & Exosomal contents (srug) & Ref. \\
\hline \multirow[t]{4}{*}{ Colorectal cancer } & miR-92a-3p (5-Fu/Oxaliplatin) & {$[55]$} \\
\hline & miR-125b (mFOLFOX6) & [139] \\
\hline & IncRNA UCA1 (Cetuximab) & [137] \\
\hline & $\begin{array}{l}\text { A panel of miR-21-5p, miR-1246, miR1229-5p and miR-96-5p (oxaliplatin and } \\
\text { 5-fluorouracil) }\end{array}$ & [138] \\
\hline \multirow[t]{7}{*}{ Prostate cancer } & ITGB4 and Vinculin (Taxane) & [141] \\
\hline & AR-V7 (Hormonal Therapy) & [144] \\
\hline & P-glycoprotein (Docetaxel) & [39] \\
\hline & CD44v8-10 mRNA (Docetaxel) & [140] \\
\hline & MDR-1, MDR-3, endophilin-A2, and PABP4 (Docetaxel) & [147] \\
\hline & miR-1290 (Docetaxel) & [148] \\
\hline & miR-34a (Docetaxel) & [142] \\
\hline \multirow[t]{7}{*}{ Breast cancer } & Survivin (Paclitaxel) & {$[76]$} \\
\hline & TRPC5 & [145] \\
\hline & TK1 and CDK9 mRNA (CDK4/6 inhibitors) & [149] \\
\hline & IncRNA-SNHG14 (Trastuzumab) & [73] \\
\hline & IncRNA AFAP1-AS1 (Trastuzumab) & [62] \\
\hline & RNA H19 (Doxorubicin) & {$[150]$} \\
\hline & GSTP1 (Adriamycin) & [136] \\
\hline Multiple myeloma & PSMA3 and IncPSMA3-AS1 (Bortezomib) & [151] \\
\hline Ovarian cancer & Plasma gelsolin (pGSN) & [152] \\
\hline \multirow[t]{2}{*}{ Pancreatic cancer } & EphA2 (Gemcitabine) & [153] \\
\hline & miR-155 (Gemcitabine) & [154] \\
\hline Head and neck cancer & miR-196a (Cisplatin) & [155] \\
\hline \multirow[t]{5}{*}{ Lung cancer } & miR-222-3p (Gemcitabine) & {$[156]$} \\
\hline & miR-146a-5p (Cisplatin) & [157] \\
\hline & miR-21 (Cisplatin) & [158] \\
\hline & miR-425-3p (Platinum-based chemotherapy) & {$[8,60]$} \\
\hline & IncRNA RP11-838N2.4 (Erlotinib) & [159] \\
\hline Melanoma & PDGFR-B (Vemurafenib) & [160] \\
\hline \multirow[t]{4}{*}{ Glioblastoma } & miR-1238 (Temozolomide) & [161] \\
\hline & miR-151a (Temozolomide) & [82] \\
\hline & MET and p-MET (Temozolomide) & [75] \\
\hline & IncSBF2-AS1 (Temozolomide) & {$[81]$} \\
\hline Gestational trophoblastic neoplasia & miR-219a-5p (Methotrexate) & [162] \\
\hline \multirow[t]{2}{*}{ Diffuse large B-cell lymphoma } & miR-146a & [163] \\
\hline & miR-99a-5p and miR-125b-5p (R-CHOP regimen) & [164] \\
\hline Renal cell carcinoma & IncARSR (Sunitinib) & [72] \\
\hline
\end{tabular}

ranging from non-coding RNAs to functional proteins through tumor cellular components by exosomes suggesting their significant role in tumor initiation and chemoresistance expansion. Exosome properties such as presence in all body's biological fluids, accessibility, high stability, and high sensitivity to reflecting the characteristics of the originating cells, has made exosomes an excellent biomarker for diagnostic and prognostic goals. In this regard, we provide a list of exosomal cargos that can be used as predictor markers of drug resistance. Exosomes as a natural capsule can also be a good tool for drug or gene delivery to overcome tumor drug resistance. Also, exosomes are suitable therapeutic targets for maximizing the efficacy of chemotherapy, therefore, searching for new chemicals or pharmacological agents that interfere with the biogenesis, secretion, and uptake of exosomes by the recipient cells is essential. 


\begin{abstract}
Abbreviations
ABCA3: ATP-binding cassette transporter A3; ALK: Anaplastic lymphoma kinase; AR-V7: Androgen receptor splice variant 7; AUF1: AU-binding factor 1; BBB: Blood-brain barrier; BCRP: Breast cancer resistance protein; CAFs: Cancerassociated fibroblasts; ceRNA: Competing endogenous RNA; CSCs: Cancer stem cells; CSF: Cerebrospinal fluid; CRC: Colorectal cancer; CRPC: Castrationresistant prostate cancer; DDR: DNA damage response; DSBs: Double-strand breaks; DLBCL: Diffuse large B-cell lymphomas; EMT: Epithelial-mesenchymal transition; ENZ: Enzalutamide; EphA2: Ephrin type-A receptor 2; ESCRT: Endosomal sorting complex required for transport proteins; FLT3: FMS-like tyrosine kinase 3; 5-Fu: 5-Fluorouracil; GBM: Glioblastoma; G-CSF: Granulocyte colony stimulating factor; GEM: Gemcitabine; GSTP1: Glutathione S-transferase P1; HCC: Hepatocellular carcinoma; HER2: Human epidermal growth factor receptor 2; HSPGs: Heparan sulfate proteoglycans; Hsps: Heat shock proteins; IAP: Inhibitor of apoptosis; ILVs: Intraluminal vesicles; ITGB4: Integrin $\beta 4$; IncRNAs: Long non-coding RNA; MDR: Multi-drug resistance; MGMT: Methyl guanine DNA methyltransferase; MRP-1: Multidrug-resistant protein-1; MVBs: Multivesicular bodies; NSCLC: Non-small cell lung cancer; OSCCs: Oral squamous carcinoma cells; P-gp: P-glycoprotein; PDCD4: Programmed cell death 4; RTK: Receptor tyrosine kinase; siRNA: Short interfering RNA; TMZ: Temozolomide; TSGs: Tumor-suppressor genes; TSG 10: Tumor susceptibility gene 101 protein; TRPC5: Transient receptor potential channel 5; VCL: Vinculin; XRCC4: X-ray repair cross complementing; TME: Tumor microenvironment.
\end{abstract}

\section{Acknowledgements}

Not applicable.

\section{Authors' contributions}

MM contributed to drafting and editing of the manuscript, shared the first authorship. NS revised and finalized the manuscript. MN and BB participated in the revision and coordination. SH contributed to the literature search. HK participated in the conception and coordination. All authors read and approved the final manuscript.

\section{Funding}

This work was financially supported by Tabriz University of medical sciences under Grant No. IR.TBZMED.REC.1397.117 and Iran National Science Foundation (INSF) (Grant No. 97014455).

\section{Availability of data and materials}

Not applicable.

Ethics approval and consent to participate

Not applicable.

\section{Consent for publication}

Not applicable.

\section{Competing interests}

The authors declare that they have no conflict of interest.

\section{Author details}

${ }^{1}$ Drug Applied Research Center, Tabriz University of Medical Sciences, Tabriz, Iran. ${ }^{2}$ Department of Biochemistry and Clinical Laboratories, Faculty of Medicine, Tabriz University of Medical Sciences, Tabriz, Iran. ${ }^{3}$ Biotechnology Research Center, Tabriz University of Medical Sciences, Tabriz, Iran. ${ }^{4}$ Department of Molecular Medicine, Faculty of Advanced Medical Sciences, Tabriz University of Medical Sciences, Tabriz, Iran. ${ }^{5}$ Immunology Research Center, Faculty of Medicine, Tabriz University of Medical Sciences, Tabriz, Iran. ${ }^{6}$ Infectious and Tropical Diseases Research Center, Tabriz University of Medical Sciences, Tabriz, Iran. ${ }^{7}$ Stem Cell and Regenerative Medicine Institute, Tabriz University of Medical Sciences, Tabriz, Iran.

Received: 17 September 2020 Accepted: 7 December 2020 Published online: 06 January 2021

\section{References}

1. Pérez-Herrero E, Fernández-Medarde A. Advanced targeted therapies in cancer: drug nanocarriers, the future of chemotherapy. Eur J Pharm Biopharm. 2015;93:52-79.

2. Si W, Shen J, Zheng H, Fan W. The role and mechanisms of action of microRNAs in cancer drug resistance. Clin Epigenetics. 2019:11(1):25-49.

3. Jeddi F, Soozangar N, Sadeghi MR, Somi MH, Shirmohamadi M, et al. Nrf2 overexpression is associated with P-glycoprotein upregulation in gastric cancer. Biomed Pharmacother. 2018;97:286-92.

4. Bebelman MP, Smit MJ, Pegtel DM, Baglio SR. Biogenesis and function of extracellular vesicles in cancer. Pharmacol Ther. 2018;188:1-11.

5. Cappello F, Logozzi M, Campanella C, Bavisotto CC, Marcilla A, et al. Exosome levels in human body fluids: a tumor marker by themselves? Eur J Pharm Biopharm. 2017;96:93-8.

6. Fais S, O'Driscoll L, Borras FE, Buzas E, Camussi G, et al. Evidence-based clinical use of nanoscale extracellular vesicles in nanomedicine. ACS Nano. 2016;10(4):3886-99.

7. Logozzi M, Angelini DF, Giuliani A, Mizzoni D, Di Raimo R, et al. Increased plasmatic levels of PSA-expressing exosomes distinguish prostate cancer patients from Benign prostatic hyperplasia: a prospective study. Cancers. 2019;11(10):1449.

8. Yuwen D, Ma Y, Wang D, Gao J, Li X, et al. Prognostic role of circulating exosomal miR-425-3p for the response of NSCLC to platinum-based chemotherapy. Cancer Epidemiol Biomarkers Prev. 2019;28(1):163-73.

9. Zhao L, Liu W, Xiao J, Cao B. The role of exosomes and "exosomal shuttle microRNA" in tumorigenesis and drug resistance. Cancer Lett. 2015;356(2 Pt B):339-46.

10. Jan AT, Rahman S, Khan S, Tasduq SA, Choi I. Biology, pathophysiological role, and clinical implications of exosomes: a critical appraisal. Cells. 2019:8(2):99. https://doi.org/10.3390/cells8020099.

11. Mathivanan S, Ji H, Simpson RJ. Exosomes: extracellular organelles important in intercellular communication. J Proteomics. 2010;73(10):1907-20

12. Agrawal AK, Aqil F, Jeyabalan J, Spencer WA, Beck J, et al. Milkderived exosomes for oral delivery of paclitaxel. Nanomedicine. 2017;13(5):1627-36.

13. Logozzi M, De Milito A, Lugini L, Borghi M, Calabro L, et al. High levels of exosomes expressing CD63 and caveolin-1 in plasma of melanoma patients. PLoS ONE. 2009;4(4):e5219.

14. Minciacchi VR, Freeman MR, Di Vizio D. Extracellular vesicles in cancer: exosomes, microvesicles and the emerging role of large oncosomes. Semin Cell Dev Biol. 2015;40:41-51.

15. Ruivo CF, Adem B, Silva M, Melo SA. The biology of cancer exosomes: insights and new perspectives. Cancer Res. 2017;77(23):6480-8.

16. Kahroba H, Hejazi MS, Samadi N. Exosomes: from carcinogenesis and metastasis to diagnosis and treatment of gastric cancer. Cell Mol Life Sci. 2019;76(9):1747-58.

17. Logozzi M, Angelini DF, lessi E, Mizzoni D, Di Raimo R, et al. Increased PSA expression on prostate cancer exosomes in in vitro condition and in cancer patients. Cancer Lett. 2017:403:318-29.

18. Hessvik NP, Llorente A. Current knowledge on exosome biogenesis and release. Cell Mol Life Sci. 2018;75(2):193-208.

19. Guan X-W, Zhao F, Wang J-Y, Wang H-Y, Ge S-H, et al. Tumor microenvironment interruption: a novel anti-cancer mechanism of proton-pump inhibitor in gastric cancer by suppressing the release of microRNAcarrying exosomes. Am J Cancer Res. 2017;7(9):1913-25.

20. Huber V, Fais S, lero M, Lugini L, Canese P, et al. Human colorectal cancer cells induce T-cell death through release of proapoptotic microvesicles: role in immune escape. Gastroenterology. 2005;128(7):1796-804.

21. Nikolaou M, Pavlopoulou A, Georgakilas AG, Kyrodimos E. The challenge of drug resistance in cancer treatment: a current overview. Clin Exp Metastasis. 2018;35(4):309-18.

22. Samadi N, Barazvan B, Rad JS. Tumor microenvironment-mediated chemoresistance in breast cancer. Breast. 2016;30:92-100.

23. Mansoori B, Mohammadi A, Davudian S, Shirjang S, Baradaran B. The different mechanisms of cancer drug resistance: a brief review. Adv Pharm Bull. 2017;7(3):339-48.

24. Lippert TH, Ruoff H-J, Volm M. Intrinsic and acquired drug resistance in malignant tumors. Arzneimittelforschung. 2008;58(06):261-4. 
25. Wu Q, Yang Z, Nie Y, Shi Y, Fan D. Multi-drug resistance in cancer chemotherapeutics: mechanisms and lab approaches. Cancer Lett. 2014;347(2):159-66.

26. Zheng H-C. The molecular mechanisms of chemoresistance in cancers. Oncotarget. 2017:8(35):59950.

27. Pillai SR, Damaghi M, Marunaka Y, Spugnini EP, Fais S, et al. Causes, consequences, and therapy of tumors acidosis. Cancer Metastasis Rev. 2019;38(1-2):205-22.

28. Bach DH, Hong JY, Park HJ, Lee SK. The role of exosomes and miRNAs in drug-resistance of cancer cells. Int J Cancer. 2017;141(2):220-30.

29. Hu Y, Yan C, Mu L, Huang K, Li X, et al. Fibroblast-derived exosomes contribute to chemoresistance through priming cancer stem cells in colorectal cancer. PLoS ONE. 2015;10(5):e0125625.

30. Wang $X$, Zhang $H$, Chen $X$. Drug resistance and combating drug resistance in cancer. Cancer Drug Resistance. 2019;2:141-60.

31. Shedden K, Xie XT, Chandaroy P, Chang YT, Rosania GR. Expulsion of small molecules in vesicles shed by cancer cells: association with gene expression and chemosensitivity profiles. Cancer Res. 2003;63(15):4331-7.

32. PeakT, Panigrahi G, Praharaj P, Chavez J, Chyr J, Singh R, Vander Griend D, Bitting R, Hemal A, Deep G. PD65-01 Do exosomes contribute to the development of enzalutamide-resistant prostate cancer. J Urol. 2018;199(4):e1224.

33. Koch R, Aung T, Vogel D, Chapuy B, Wenzel D, et al. Nuclear trapping through inhibition of exosomal export by indomethacin increases cytostatic efficacy of doxorubicin and pixantrone. Clin Cancer Res. 2016;22(2):395-404

34. Wang J, Yeung BZ, Cui M, Peer CJ, Lu Z, et al. Exosome is a mechanism of intercellular drug transfer: application of quantitative pharmacology. J Control Release. 2017;268:147-58.

35. Luciani F, Molinari A, Lozupone F, Calcabrini A, Lugini L, et al. P-glycoprotein-actin association through ERM family proteins: a role in P-glycoprotein function in human cells of lymphoid origin. Blood. 2002;99(2):641-8

36. Marin JJ, Lozano E, Herraez E, Asensio M, Di Giacomo S, et al. Chemoresistance and chemosensitization in cholangiocarcinoma. Biochim Biophys Acta. 2018;1864(4):1444-53.

37. Bebawy M, Combes V, Lee E, Jaiswal R, Gong J, et al. Membrane microparticles mediate transfer of P-glycoprotein to drug sensitive cancer cells. Leukemia. 2009;23(9):1643-9.

38. Corcoran C, Rani S, O'Brien K, O'Neill A, Prencipe M, et al. Docetaxelresistance in prostate cancer: evaluating associated phenotypic changes and potential for resistance transfer via exosomes. PLOS ONE. 2012;7(12):1-11.

39. Kato T, Mizutani K, Kameyama K, Kawakami K, Fujita Y, et al. Serum exosomal P-glycoprotein is a potential marker to diagnose docetaxel resistance and select a taxoid for patients with prostate cancer. Urol Oncol. 2015;33(9):385.e15-20.

40. Lopes-Rodrigues V, Di Luca A, Sousa D, Seca H, Meleady P, et al. Multidrug resistant tumour cells shed more microvesicle-like EVs and less exosomes than their drug-sensitive counterpart cells. Biochim Biophys Acta. 2016;1860(3):618-27.

41. Lv MM, Zhu XY, Chen WX, Zhong SL, Hu Q, et al. Exosomes mediate drug resistance transfer in MCF-7 breast cancer cells and a probable mechanism is delivery of P-glycoprotein. Tumour Biol. 2014;35(11):10773-9.

42. Ning K, Wang T, Sun X, Zhang P, Chen Y, et al. UCH-L1-containing exosomes mediate chemotherapeutic resistance transfer in breast cancer. J Surg Oncol. 2017;115(8):932-40.

43. Torreggiani E, Roncuzzi L, Perut F, Zini N, Baldini N. Multimodal transfer of MDR by exosomes in human osteosarcoma. Int J Oncol. 2016;49(1):189-96.

44. Wang X, Xu C, Hua Y, Sun L, Cheng K, et al. Exosomes play an important role in the process of psoralen reverse multidrug resistance of breast cancer. J Exp Clin Cancer Res. 2016;35(1):1-10.

45. Kibria $\mathrm{G}$, Hatakeyama $\mathrm{H}$, Harashima $\mathrm{H}$. Cancer multidrug resistance: mechanisms involved and strategies for circumvention using a drug delivery system. Arch Pharm Res. 2014;37(1):4-15.

46. Prieto-Vila M, Takahashi R, Usuba W, Kohama I, Ochiya T. Drug resistance driven by cancer stem cells and their niche. Int J Mol Sci. 2017:18(12):2574.
47. Smith AG, Macleod KF. Autophagy, cancer stem cells and drug resistance. J Pathol. 2019;247(5):708-18.

48. Todaro M, Alea MP, Di Stefano AB, Cammareri P, Vermeulen L, et al. Colon cancer stem cells dictate tumor growth and resist cell death by production of interleukin-4. Cell Stem Cell. 2007;1(4):389-402.

49. Wilson BJ, Schatton T, Zhan Q, Gasser M, Ma J, et al. ABCB5 identifies a therapy-refractory tumor cell population in colorectal cancer patients. Cancer Res. 2011;71(15):5307-16.

50. Friedmann-Morvinski D, Verma IM. Dedifferentiation and reprogramming: origins of cancer stem cells. EMBO Rep. 2014;15(3):244-53.

51. You J, Li M, Cao L, Gu Q, Deng P, et al. Snail1-dependent cancerassociated fibroblasts induce epithelial-mesenchymal transition in lung cancer cells via exosomes. QJM-INT J MED. 2019;112(8):581-90.

52. Rodrigues CF, Serrano E, Patrício MI, Val MM, Albuquerque $P$, et al. Stroma-derived IL-6, G-CSF and Activin-A mediated dedifferentiation of lung carcinoma cells into cancer stem cells. Sci Rep. 2018:8(1):1-12.

53. Hu YB, Yan C, Mu L, Mi YL, Zhao H, et al. Exosomal Wnt-induced dedifferentiation of colorectal cancer cells contributes to chemotherapy resistance. Oncogene. 2019;38(11):1951-65.

54. Santos JC, Lima NDS, Sarian LO, Matheu A, Ribeiro ML, et al. Exosomemediated breast cancer chemoresistance via miR-155 transfer. Sci Rep. 2018;8(1):1-11.

55. Hu JL, Wang W, Lan XL, Zeng ZC, Liang YS, et al. CAFs secreted exosomes promote metastasis and chemotherapy resistance by enhancing cell stemness and epithelial-mesenchymal transition in colorectal cancer. Mol Cancer. 2019;18(1):1-15.

56. Huang Z, Zhou L, Chen Z, Nice EC, Huang C. Stress management by autophagy: implications for chemoresistance. Int J Cancer 2016;139(1):23-32.

57. Milman N, Ginini L, Gil Z. Exosomes and their role in tumorigenesis and anticancer drug resistance. Drug Resist Updat. 2019:45:1-12.

58. Mortezavi A, Salemi S, Kranzbühler B, Gross O, Sulser T, et al. Inhibition of autophagy significantly increases the antitumor effect of Abiraterone in prostate cancer. World J Urol. 2019;37(2):351-8.

59. Li XQ, Liu JT, Fan LL, Liu Y, Cheng L, et al. Exosomes derived from gefitinib-treated EGFR-mutant lung cancer cells alter cisplatin sensitivity via up-regulating autophagy. Oncotarget. 2016;7(17):24585-95.

60. Ma Y, Yuwen D, Chen J, Zheng B, Gao J, et al. Exosomal transfer of cisplatin-induced miR-425-3p confers cisplatin resistance in NSCLC through activating autophagy. Int J Nanomed. 2019;14:8121.

61. Liu DX, Li PP, Guo JP, Li LL, Guo B, et al. Exosomes derived from HBVassociated liver cancer promote chemoresistance by upregulating chaperone-mediated autophagy. Oncol Lett. 2019;17(1):323-31.

62. Han M, Gu Y, Lu P, Li J, Cao H, et al. Exosome-mediated IncRNA AFAP1AS1 promotes trastuzumab resistance through binding with AUF1 and activating ERBB2 translation. Mol Cancer. 2020;19(1):1-18.

63. Xu J-H, Hu S-L, Shen G-D, Shen G. Tumor suppressor genes and their underlying interactions in paclitaxel resistance in cancer therapy. Cancer Cell Int. 2016;16(1):1-10.

64. Setoguchi K, TeSlaa T, Koehler CM, Teitell MA. P53 regulates rapid apoptosis in human pluripotent stem cells. J Mol Biol. 2016:428(7):1465-75.

65. Cao Z, Xu L, Zhao S. Exosome-derived miR-27a produced by PSC27cells contributes to prostate cancer chemoresistance through p53. Biochem Biophys Res Commun. 2019;515(2):345-51.

66. Fu X, Liu M, Qu S, Ma J, Zhang Y, et al. Exosomal microRNA-32-5p induces multidrug resistance in hepatocellular carcinoma via the PI3K Akt pathway. J Exp Clin Cancer Res. 2018;37(1):1-18.

67. Yin J, Zeng A, Zhang Z, Shi Z, Yan W, et al. Exosomal transfer of miR-1238 contributes to temozolomide-resistance in glioblastoma. EBioMedicine. 2019:42:238-51.

68. Fang $Y$, Zhou W, Rong $Y$, Kuang T, Xu X, et al. Exosomal miRNA-106b from cancer-associated fibroblast promotes gemcitabine resistance in pancreatic cancer. Exp Cell Res. 2019;383(1):111543.

69. Wang M, Qiu R, Yu S, Xu X, Li G, et al. Paclitaxelresistant gastric cancer MGC803 cells promote epithelial to mesenchymal transition and chemoresistance in paclitaxel sensitive cells via exosomal delivery of miR1555p. Int J Oncol. 2019;54(1):326-38.

70. Kang M, Ren M, Li Y, Fu Y, Deng M, et al. Exosome-mediated transfer of IncRNA PART1 induces gefitinib resistance in esophageal squamous cell carcinoma via functioning as a competing endogenous RNA. J Exp Clin Cancer Res. 2018:37(1):171. 
71. Xu CG, Yang MF, Ren YQ, Wu CH, Wang LQ. Exosomes mediated transfer of IncRNA UCA1 results in increased tamoxifen resistance in breast cancer cells. Eur Rev Med Pharmacol Sci. 2016;20(20):4362-8.

72. Qu L, Ding J, Chen C, Wu ZJ, Liu B, et al. Exosome-transmitted IncARSR promotes sunitinib resistance in renal cancer by acting as a competing endogenous RNA. Cancer Cell. 2016;29(5):653-68.

73. Dong H, Wang W, Chen R, Zhang Y, Zou K, et al. Exosome-mediated transfer of IncRNASNHG14 promotes trastuzumab chemoresistance in breast cancer. Int J Oncol. 2018:53(3):1013-26.

74. Deng X, Ruan H, Zhang X, Xu X, Zhu Y, et al. Long non-coding RNA CCAL transferred from fibroblasts by exosomes promotes chemoresistance of colorectal cancer cells. Int J Cancer. 2019;29(5):653-68.

75. Zeng A, Yan W, Liu Y, Wang Z, Hu Q, et al. Tumour exosomes from cells harbouring PTPRZ1-MET fusion contribute to a malignant phenotype and temozolomide chemoresistance in glioblastoma. Oncogene. 2017;36(38):5369-81.

76. Kreger BT, Johansen ER, Cerione RA, Antonyak MA. The enrichment of survivin in exosomes from breast cancer cells treated with paclitaxel promotes cell survival and chemoresistance. Cancers. 2016;8(12):1-14.

77. Cesi G, Philippidou D, Kozar I, Kim YJ, Bernardin F, et al. A new ALK isoform transported by extracellular vesicles confers drug resistance to melanoma cells. Mol Cancer. 2018;17(1):145.

78. Zhang Q, Liu RX, Chan KW, Hu J, Zhang J, et al. Exosomal transfer of p-STAT3 promotes acquired 5-FU resistance in colorectal cancer cells. J Exp Clin Cancer Res. 2019;38(1):1-14.

79. O'Connor MJ. Targeting the DNA damage response in cancer. Mol Cell. 2015;60(4):547-60.

80. Tian H, Gao Z, Li H, Zhang B, Wang G, et al. DNA damage response-a double-edged sword in cancer prevention and cancer therapy. Cancer Lett. 2015;358(1):8-16.

81. Zhang Z, Yin J, Lu C, Wei Y, Zeng A, et al. Exosomal transfer of long noncoding RNA SBF2-AS1 enhances chemoresistance to temozolomide in glioblastoma. J Exp Clin Cancer Res. 2019;38(1):166.

82. Zeng A, Wei Z, Yan W, Yin J, Huang X, et al. Exosomal transfer of miR151a enhances chemosensitivity to temozolomide in drug-resistant glioblastoma. Cancer Lett. 2018:436:10-21.

83. Yu T, Wang $X$, Zhi T, Zhang J, Wang $Y$, et al. Delivery of MGMT mRNA to glioma cells by reactive astrocyte-derived exosomes confers a temozolomide resistance phenotype. Cancer Lett. 2018;433:210-20.

84. Logozzi M, Spugnini E, Mizzoni D, Di Raimo R, Fais S. Extracellular acidity and increased exosome release as key phenotypes of malignant tumors. Cancer Metastasis Rev. 2019;38(1-2):93-101.

85. Gillies RJ, Pilot C, Marunaka Y, Fais S. Targeting acidity in cancer and diabetes. Biochim Biophys Acta Rev Cancer. 2019;1871(2):273-80.

86. Fais $\mathrm{S}$, Venturi $\mathrm{G}$, Gatenby B. Microenvironmental acidosis in carcinogenesis and metastases: new strategies in prevention and therapy. Cancer Metastasis Rev. 2014;33(4):1095-108.

87. Logozzi M, Mizzoni D, Capasso C, Del Prete S, Di Raimo R, et al. Plasmatic exosomes from prostate cancer patients show increased carbonic anhydrase IX expression and activity and low pH. J Enzyme Inhib Med Chem. 2020:35(1):280-8

88. Parolini I, Federici C, Raggi C, Lugini L, Palleschi S, et al. Microenvironmental pH is a key factor for exosome traffic in tumor cells. J Biol Chem. 2009;284(49):34211-22.

89. Logozzi M, Mizzoni D, Angelini DF, Di Raimo R, Falchi M, et al. Microenvironmental pH and exosome levels interplay in human cancer cell lines of different histotypes. Cancers. 2018;10(10):370.

90. Peak TC, Panigrahi GK, Praharaj PP, Su Y, Shi L, et al. Syntaxin 6-mediated exosome secretion regulates enzalutamide resistance in prostate cancer. Mol Carcinog. 2020;59(1):62-72.

91. Wu C, Silvers C, Guancial E, Hsu J-W, Messing E, et al. Abstract 5475: cancer exosome promotes cisplatin resistance In bladder cancer and inhibition of exosome sensitizes bladder cancer cells to cisplatin chemotherapy. Cancer Res. 2015;75(15 Supplement):5475-5475.

92. Logozzi M, Capasso C, Di Raimo R, Del Prete S, Mizzoni D, et al. Prostate cancer cells and exosomes in acidic condition show increased carbonic anhydrase IX expression and activity. J Enzyme Inhib Med Chem. 2019;34(1):272-8

93. Fais S, Logozzi M, Lugini L, Federici C, Azzarito T, et al. Exosomes: the ideal nanovectors for biodelivery. Biol Chem. 2013;394(1):1-15.
94. Azzarito T, Lugini L, Spugnini EP, Canese R, Gugliotta A, et al. Effect of modified alkaline supplementation on syngenic melanoma growth in CB57/BL mice. PLoS ONE. 2016:11(7):e0159763.

95. Spugnini EP, Buglioni S, Carocci F, Francesco M, Vincenzi B, et al. High dose lansoprazole combined with metronomic chemotherapy: a phase I/II study in companion animals with spontaneously occurring tumors. J Transl Med. 2014;12(1):225.

96. Federici C, Petrucci F, Caimi S, Cesolini A, Logozzi M, et al. Exosome release and low $\mathrm{pH}$ belong to a framework of resistance of human melanoma cells to cisplatin. PLoS ONE. 2014;9(2):e88193.

97. Ciravolo V, Huber V, Ghedini GC, Venturelli E, Bianchi F, et al. Potential role of HER2-overexpressing exosomes in countering trastuzumabbased therapy. J Cell Physiol. 2012;227(2):658-67.

98. Aung T, Chapuy B, Vogel D, Wenzel D, Oppermann M, et al. Exosomal evasion of humoral immunotherapy in aggressive B-cell lymphoma modulated by ATP-binding cassette transporter A3. Proc Natl Acad Sci USA. 2011;108(37):15336-41.

99. Datta A, Kim H, Lal M, McGee L, Johnson A, et al. Manumycin A suppresses exosome biogenesis and secretion via targeted inhibition of Ras/Raf/ERK1/2 signaling and hnRNP H1 in castration-resistant prostate cancer cells. Cancer Lett. 2017;408:73-81.

100. Khan FM, Saleh E, Alawadhi H, Harati R, Zimmermann WH, et al. Inhibition of exosome release by ketotifen enhances sensitivity of cancer cells to doxorubicin. Cancer Biol Ther. 2018;19(1):25-33.

101. Kosgodage U, Trindade R, Thompson P, Inal J, Lange S. Chloramidine/ bisindolylmaleimide-l-mediated inhibition of exosome and microvesicle release and enhanced efficacy of cancer chemotherapy. Int J Mol Sci. 2017;18(5):1007.

102. To KK, Tong CW, Wu MM, Yan W. Abstract 3814: overcoming multidrug resistance (MDR) in colorectal cancer by modulating exosome-mediated transfer of MDR transporter regulatory machineries. Cancer Res. 2019;79(13 Supplement):3814-3814.

103. Christianson HC, Belting M. Heparan sulfate proteoglycan as a cellsurface endocytosis receptor. Matrix Biol. 2014;35:51-5.

104. Sento S, Sasabe E, Yamamoto T. Application of a persistent heparin treatment inhibits the malignant potential of oral squamous carcinoma cells induced by tumor cell-derived exosomes. PLOS ONE. 2016;11(2):e0148454

105. Zhao H, Yang L, Baddour J, Achreja A, Bernard V, et al. Tumor microenvironment derived exosomes pleiotropically modulate cancer cell metabolism. elife. 2016;5:e10250.

106. Chiba M, Kubota S, Sato K, Monzen S. Exosomes released from pancreatic cancer cells enhance angiogenic activities via dynamin-dependent endocytosis in endothelial cells in vitro. Sci Rep. 2018;8(1):11972.

107. Li Y, Gao Y, Gong C, Wang Z, Xia Q, et al. A33 antibody-functionalized exosomes for targeted delivery of doxorubicin against colorectal cancer. Nanomedicine. 2018;14(7):1973-85.

108. Tian T, Zhu Y-L, Zhou Y-Y, Liang G-F, Wang Y-Y, et al. Exosome uptake through clathrin-mediated endocytosis and macropinocytosis and mediating miR-21 delivery. J Biol Chem. 2014;289(32):22258-67.

109. Hazan-Halevy I, Rosenblum D, Weinstein S, Bairey O, Raanani P, et al. Cell-specific uptake of mantle cell lymphoma-derived exosomes by malignant and non-malignant B-lymphocytes. Cancer Lett. 2015;364(1):59-69.

110. Yang YC, Liu GJ, Yuan DF, Li CQ, Xue M, et al. Influence of exosomederived miR-21 on chemotherapy resistance of esophageal cancer. Eur Rev Med Pharmacol Sci. 2019;23(4):1513-9.

111. Zhang Y, Li M, Hu C. Exosomal transfer of miR-214 mediates gefitinib resistance in non-small cell lung cancer. Biochem Biophys Res Commun. 2018;507(1-4):457-64.

112. Kim MS, Haney MJ, Zhao Y, Yuan D, Deygen I, et al. Engineering macrophage-derived exosomes for targeted paclitaxel delivery to pulmonary metastases: in vitro and in vivo evaluations. Nanomedicine. 2018;14(1):195-204.

113. Bunggulawa EJ, Wang W, Yin T, Wang N, Durkan C, et al. Recent advancements in the use of exosomes as drug delivery systems. $J$ Nanobiotechnology. 2018;16(1):1-13.

114. Kim MS, Haney MJ, Zhao Y, Mahajan V, Deygen I, et al. Development of exosome-encapsulated paclitaxel to overcome MDR in cancer cells. Nanomedicine. 2016;12(3):655-64. 
115. Saari H, Lázaro-Ibáñez E, Viitala T, Vuorimaa-Laukkanen E, Siljander P, et al. Microvesicle-and exosome-mediated drug delivery enhances the cytotoxicity of Paclitaxel in autologous prostate cancer cells. J Control Release. 2015;220:727-37.

116. Hadla M, Palazzolo S, Corona G, Caligiuri I, Canzonieri V, et al. Exosomes increase the therapeutic index of doxorubicin in breast and ovarian cancer mouse models. Nanomedicine. 2016;11(18):2431-41. https:// doi.org/10.2217/nnm-2016-0154.

117. Rizzolio F, Hadla M, Corona G, Caligiuri I, Palazzolo S, et al. Abstract 2205: exosomal encapsulation of doxorubicin reduces the cardiac toxicity of mice. Cancer Res. 2016;76(14 Supplement):2205.

118. Toffoli G, Hadla M, Corona G, Caligiuri I, Palazzolo S, et al. Exosomal doxorubicin reduces the cardiac toxicity of doxorubicin. Nanomedicine. 2015;10(19):2963-71. https://doi.org/10.2217/nnm.15.118.

119. Yang T, Martin P, Fogarty B, Brown A, Schurman K, et al. Exosome delivered anticancer drugs across the blood-brain barrier for brain cancer therapy in Danio rerio. Pharm Res. 2015;32(6):2003-14. https://doi. org/10.1007/s11095-014-1593-y.

120. Munagala R, Aqil F, Jeyabalan J, Gupta RC. Bovine milk-derived exosomes for drug delivery. Cancer Lett. 2016;371(1):48-61.

121. Iessi E, Logozzi M, Lugini L, Azzarito T, Federici C, et al. Acridine orange/ exosomes increase the delivery and the effectiveness of Acridine Orange in human melanoma cells: a new prototype for theranostics of tumors. J Enzyme Inhib Med Chem. 2017;32(1):648-57.

122. Li H, Yang C, Shi Y, Zhao L. Exosomes derived from siRNA against GRP78 modified bone-marrow-derived mesenchymal stem cells suppress Sorafenib resistance in hepatocellular carcinoma. J Nanobiotechnol. 2018;16(1):103.

123. O'Brien K, Lowry MC, Corcoran C, Martinez VG, Daly M, et al. miR-134 in extracellular vesicles reduces triple-negative breast cancer aggression and increases drug sensitivity. Oncotarget. 2015;6(32):32774-89.

124. Lou G, Song X, Yang F, Wu S, Wang J, et al. Exosomes derived from miR122-modified adipose tissue-derived MSCs increase chemosensitivity of hepatocellular carcinoma. J Hematol Oncol. 2015;8(1):122.

125. Lou G, Liu Y, Zhang T, Li S, Chen Z, et al. Exosome derived from miR199*-modified adipose tissue-derived MSCs increase chemosensitivity of hepatocellular carcinoma. J Hepatol. 2018;68:S685.

126. Munoz JL, Bliss SA, Greco SJ, Ramkissoon SH, Ligon KL, et al. Delivery of functional anti-miR-9 by mesenchymal stem cell-derived exosomes to glioblastoma multiforme cells conferred chemosensitivity. Mol Ther Nucleic Acids. 2013;2(e126):1-11.

127. Wang G, Zhao W, Wang H, Qiu G, Jiang Z, et al. Exosomal MiR-744 inhibits proliferation and sorafenib chemoresistance in hepatocellular carcinoma by targeting PAX2. Med Sci Monit. 2019;25:7209.

128. Katakowski M, Buller B, Zheng X, Lu Y, Rogers T, et al. Exosomes from marrow stromal cells expressing miR-146b inhibit glioma growth. Cancer Lett. 2013;335(1):201-4.

129. Liang G, Zhu Y, Ali DJ, Tian T, Xu H, et al. Engineered exosomes for targeted co-delivery of miR-21 inhibitor and chemotherapeutics to reverse drug resistance in colon cancer. J Nanobiotechnology. 2020;18(1):1-15.

130. El Bairi K, Atanasov AG, Amrani M, Afqir S. The arrival of predictive biomarkers for monitoring therapy response to natural compounds in cancer drug discovery. Biomed Pharmacother. 2019;109:2492-8.

131. Logozzi M, Mizzoni D, Di Raimo R, Fais S. Exosomes: a source for new and old biomarkers in cancer. Cancers. 2020;12(9):2566.

132. Osti D, Del Bene M, Rappa G, Santos M, Matafora V, et al. Clinical significance of extracellular vesicles in plasma from glioblastoma patients. Clin Cancer Res. 2019;25(1):266-76.

133. Properzi F, Logozzi M, Fais S. Exosomes: the future of biomarkers in medicine. Biomark Med. 2013;7(5):769-78.

134. Rodríguez Zorrilla S, Pérez-Sayans M, Fais S, Logozzi M, Gallas Torreira $M$, et al. A pilot clinical study on the prognostic relevance of plasmatic exosomes levels in oral squamous cell carcinoma patients. Cancers. 2019;11(3):429.

135. Huang X, Yuan T, Liang M, Du M, Xia S, et al. Exosomal miR-1290 and miR-375 as prognostic markers in castration-resistant prostate cancer. Eur Urol. 2015;67(1):33-41. https://doi.org/10.1016/j.eururo.2014.07.035.

136. Yang SJ, Wang DD, Li J, Xu HZ, Shen HY, et al. Predictive role of GSTP1containing exosomes in chemotherapy-resistant breast cancer. Gene. 2017;623:5-14. https://doi.org/10.1016/j.gene.2017.04.031.
137. Yang YN, Zhang R, Du JW, Yuan HH, Li YJ, et al. Predictive role of UCA1containing exosomes in cetuximab-resistant colorectal cancer. Cancer Cell Int. 2018;18:164.

138. Jin G, Liu Y, Zhang J, Bian Z, Yao S, et al. A panel of serum exosomal microRNAs as predictive markers for chemoresistance in advanced colorectal cancer. Cancer Chemother Pharmacol. 2019;84:1-11.

139. Yagi T, linuma H, Hayama T, Matsuda K, Nozawa K, et al. Plasma exosomal microRNA-125b as a monitoring biomarker of resistance to mFOLFOX6-based chemotherapy in advanced and recurrent colorectal cancer patients. Mol Clin Oncol. 2019;1 1(4):416-24.

140. Kato T, Mizutani K, Horie K, Kawakami K, Fujita Y, et al. The cluster of differentiation 44 variant 8-10 messenger RNA contained in exosomes is a potential marker for docetaxel resistance among prostate cancer patients. Eur Urol Suppl. 2019;18(1):e473.

141. Kawakami K, Fujita Y, Kato T, Mizutani K, Kameyama K, et al. Integrin beta4 and vinculin contained in exosomes are potential markers for progression of prostate cancer associated with taxane-resistance. Int J Oncol. 2015;47(1):384-90.

142. Corcoran C, Rani S, O'Driscoll L. miR-34a is an intracellular and exosomal predictive biomarker for response to docetaxel with clinical relevance to prostate cancer progression. Prostate. 2014;74(13):1320-34.

143. Shenoy NK, Wang L, Huang C-C, Kohli M. Exosomal miR-1290 as a predictive biomarker for docetaxel response in metastatic castration resistant prostate cancer (mCRPC). J Clin Oncol. 2016;34(15_suppl):e16596.

144. Del Re M, Biasco E, Crucitta S, Derosa L, Rofi E, et al. The detection of androgen receptor splice variant 7 in plasma-derived exosomal RNA strongly predicts resistance to hormonal therapy in metastatic prostate cancer patients. Eur Urol. 2017;71(4):680-7.

145. Wang T, Ning K, Lu TX, Sun X, Jin L, et al. Increasing circulating exosomes-carrying TRPC5 predicts chemoresistance in metastatic breast cancer patients. Cancer Sci. 2017;108(3):448-54.

146. Fan J, Wei Q, Koay EJ, Liu Y, Zhao Z, et al. Abstract 585: exosomal EphA2 transmits chemoresistance and predicts pancreatic cancer patient responses to therapy. Cancer Res. 2018;78(13 Supplement):585.

147. Kharaziha P, Chioureas D, Rutishauser D, Baltatzis G, Lennartsson L, et al. Molecular profiling of prostate cancer derived exosomes may reveal a predictive signature for response to docetaxel. Oncotarget. 2015;6(25):21740-54.

148. Shenoy NK, Wang L, Huang C-C, Kohli M. Exosomal miR-1290 as a predictive biomarker for docetaxel response in metastatic castration resistant prostate cancer (mCRPC). Am Soc Clin Oncol. 2016. https://doi. org/10.1200/JCO.2016.34.15_suppl.e16596.

149. Del Re M, Bertolini I, Crucitta S, Fontanelli L, Rofi E, et al. Overexpression of TK1 and CDK9 in plasma-derived exosomes is associated with clinical resistance to $C D K 4 / 6$ inhibitors in metastatic breast cancer patients. Breast Cancer Res Treat. 2019;178(1):57-62.

150. Wang X, Pei X, Guo G, Qian X, Dou D, et al. Exosome-mediated transfer of long noncoding RNA $\mathrm{H} 19$ induces doxorubicin resistance in breast cancer. J Cell Physiol. 2020;235(10):6896-904.

151. Xu H, Han H, Song S, Yi N, Qiu Y, et al. Exosome-transmitted PSMA3 and PSMA3-AS1 promote proteasome inhibitor resistance in multiple myeloma. Clin Cancer Res. 2019;25(6):1923-35.

152. Asare-Werehene M, Nakka K, Reunov A, Chiu C-T, Lee W-T, et al. The exosome-mediated autocrine and paracrine actions of plasma gelsolin in ovarian cancer chemoresistance. Oncogene. 2020;39(7):1600-16.

153. Fan J, Wei Q, Koay E J, Liu Y, Zhao Z, et al., Exosomal EphA2 transmits chemoresistance and predicts pancreatic cancer patient responses to therapy. 2018, AACR.

154. Mikamori M, Yamada D, Eguchi H, Hasegawa S, Kishimoto T, et al. MicroRNA-155 controls exosome synthesis and promotes gemcitabine resistance in pancreatic ductal adenocarcinoma. Sci Rep. 2017;7:42339.

155. Qin X, Guo H, Wang X, Zhu X, Yan M, et al. Exosomal miR-196a derived from cancer-associated fibroblasts confers cisplatin resistance in head and neck cancer through targeting CDKN1B and ING5. Genome Biol. 2019;20(1):12

156. Wei F, Ma C, Zhou T, Dong X, Luo Q, et al. Exosomes derived from gemcitabine-resistant cells transfer malignant phenotypic traits via delivery of miRNA-222-3p. Mol Cancer. 2017;16(1):132.

157. Yuwen D, Sheng B, Liu J, Wenyu W, Shu Y. MiR-146a-5p level in serum exosomes predicts therapeutic effect of cisplatin in non-small cell lung cancer. Eur Rev Med Pharmacol Sci. 2017;21(11):2650-8. 
158. Dong C, Liu X, Wang H, Li J, Dai L, et al. Hypoxic non-small-cell lung cancer cell-derived exosomal miR-21 promotes resistance of normoxic cell to cisplatin. OncoTargets Ther. 2019;12:1947.

159. Zhang W, Cai X, Yu J, Lu X, Qian Q, et al. Exosome-mediated transfer of IncRNA RP1 1838N2.4 promotes erlotinib resistance in non-small cell lung cancer. Int J Oncol. 2018;53(2):527-38.

160. Goedert L, Koya R, Hu-Lieskovan S, Ribas A. Exosomes as a predictor tool of acquired resistance to melanoma treatment. BMC Proc. 2014;8:1-2.

161. Kourembanas S. Exosomes: vehicles of intercellular signaling, biomarkers, and vectors of cell therapy. Annu Rev Physiol. 2015;77:13-27.

162. Weng Y, Shen X, Xie X, Cheng X, LvW, et al. Exosomal mir-219a-5p as a potential predictive biomarker for gestational trophoblastic neoplasia chemotherapy resistance. Gynecol Oncol. 2019;154:97.
163. Zare N, Eskandari N, Mehrzad V, Javanmard SH. The expression level of hsa-miR-146a-5p in plasma-derived exosomes of patients with diffuse large B-cell lymphoma. J Res Med Sci. 2019;24:10.

164. Feng $Y$, Zhong M, Zeng S, Wang L, Liu P, et al. Exosome-derived miRNAs as predictive biomarkers for diffuse large B-cell lymphoma chemotherapy resistance. Epigenomics. 2019;11(1):35-51.

\section{Publisher's Note}

Springer Nature remains neutral with regard to jurisdictional claims in published maps and institutional affiliations.
Ready to submit your research? Choose BMC and benefit from:

- fast, convenient online submission

- thorough peer review by experienced researchers in your field

- rapid publication on acceptance

- support for research data, including large and complex data types

- gold Open Access which fosters wider collaboration and increased citations

- maximum visibility for your research: over 100M website views per year

At BMC, research is always in progress.

Learn more biomedcentral.com/submissions 